\title{
BUSINESS GRANTS SOURCES IN THE CONTEXT OF JOINING THE EUROPEAN UNION
}

\author{
Professor Ph.D. Moise Ioan Achim, \\ “1Decembrie 1918” University Alba Iulia \\ Assistant Ph.D. Student Larisa Dragolea \\ “1Decembrie 1918” University Alba Iulia
}

\begin{abstract}
In the actual context, the capital is the main production factor and the development of businesses has become practically impossible without taking into consideration the financial market and the resources it is providing to the economic agents. Any kind of business, regardless of its development, implies a direct contact with the financial market, more exactly with the institutions which intermediate the capital resources' mobilization and of the services it's providing.

Understanding the way the financial system works, the specific financial mechanisms used when allocating saved capitals for the sustainment of investments and understanding the involved costs and risks becomes essential for the development of a business on solid ground. At its turn, the financial system is subjected to permanent changes and adapts to the new demands of the economic agents by offering them the financial resources they need in conditions of maximum efficiency in terms of risks and costs.

In this writing we will try to do a presentation and to enlarge upon the main type of non-refundable financing instruments that an entrepreneur can access with the purpose to start and develop a business.
\end{abstract}

The small and medium-size enterprises' (SME) financing has cover a long way in the last 15 years in Romania. Still, like in other countries from the region, there is still a long way to go until we will reach a suitable support for the developing potential of the SMEs. It's not only about the small number of SMEs in Romania that are responsible for a little more over $50 \%$ of the Gross Domestic Product (GDP), while in the European Union SMEs produce over $70 \%$ of the GDP, it's about their long term endurance and viability. Bonuses like reduced tariffs, technical assistance, special subventions etc. are necessary, but they must be implemented and monitored with care in order to modify the sustainment of the SMEs' developing.

There are four different stages / phase in the development of a SME until its transformation / change in an established enterprise: 1. the beginning stage, 2 . the micro stage, 3. "small" enterprises, 4. developing "medium-sized" enterprises. Thus, when financing a SME it must be taken into account that these different stages need different types of financing, with different terms and conditions. Bank loans are relevant for stages 3 and 4, and less relevant for the first two which can benefit mostly from money loans and the financing of the risk capital. Generally, subvention schemes have a limited function, with a single pull and are not tied to any long term sustainable assistance programs for SMEs. Additionally, they can't develop new financial institutions for SMEs assistance.

Nevertheless, they can be a major catalyst for the enterprises with a limited capital in the first stage, and they can ask for specific financing for a future development for the enterprises in stage two. They can also be used to offer the necessary guarantee for obtaining credits together with the guarantee funds for loans. If less than $25 \%$ of all SMEs turn to financing credits, than a big part of the market would be covered. Still, on both the demand side and the supply side there are numerous reasons why the volumes are not big. Because of 
the guarantee requirements imposed by the National Bank (for example, a minimum of $120 \%$ plus the interest from the credit's value) it is difficult for a SME to find a financing program, even in the well-developed countries. Then there is a long registering process of the guarantees in compliance with the legal stipulations. Thus, it is not surprising that in Romania this sector is not better developed. The guarantee funds that are available to fill the guarantee request don't offer clear solutions. The funds can cover the entire Romanian territory through its stock holders and through the banks it collaborates with. Because of bureaucracy, difficult procedures, time lines and/or expenses included in obtaining the guaranties from the funds for the SME, most enterprises are opposed to these approaches.

Although there are many agreements for the SME sector with most active banks in Romania, this solution is still not viable. The financing schemes can be considered useful only if they reach the targeted market and are correctly implemented. Each scheme has a good side and a bad side, but, considering the large number of financing request for SMEs that are in different stages, none of them can serve as a model for future schemes. Combined with the regional differences and the legal modifications there is no common denominator for them.

Joining the European Union has brought Romania numerous non-refundable financing opportunities (grants) for small and medium-sized businesses that were not available before.

The small and medium-seized enterprises (SMEs) in Romania will be able to access structural and cohesion funds for a total value of 580 million Euros, in the 2007-2013 period. The financing is ensured by the European Regional Development Fund (ERDF) on the basis of the program documents negotiated with the EU. The projects are selected, signed and forwarded for financing to the National Agency for Small and Medium-Seized Enterprises and Cooperation (NASMEC) with the support of its subsidiaries, and the financing will be done partially or totally after the finalization. The financing funds' administration for projects of national interest is carried and coordinated by the Management Authority inside the Economy and Commerce Minister. Studies have shown that not all SMEs and microenterprises from Romania are sufficiently prepared to be competitive on the unique European market. Most times the absence of competitiveness is caused by their incapacity to access the financing sources destined for investments in new technologies and not in the implementation of quality systems, or to benefit of consulting services that will offer the proper orientation o the market.

In this context, the Romanian Government decided to sustain the SMEs, especially by facilitating the access to capitals and to technological development. This will allow them to align to the quality standards of the European products and services.

The National Agency for Small and Medium-Seized Enterprises and Cooperation makes available for the small businesses an instrument that can prove useful in accessing the funds and in obtaining development credits in a sector where often the banks' are accused of reticence. The sources assistance guide for SMEs makes a presentation of all the refundable and non-refundable financing programs specific for this type of business; it also presents the necessary documents, the accessing conditions and the contact persons. The guide is structured in nine chapters: Basic Information, Professional Services, Counseling and Direct Support, Specific Training for SMEs, Credits, Grants, Guarantees, Locations \& Environment and Strategic Services.

SMEs can get 18 types of advantageous credits, most of them with subsidized interest. For example, a new-established company which hires unemployed people in a proportion of at least $50 \%$ from the total number of employees can get from the National Agency for Labor Force Employment a credit with an interest of 50\% from the base lending rate of the National Bank of Romania (NBR), if it activates in the counties where the unemployment rate is under or equal to the average rate at national level. For the counties with unemployment rate higher than the average national rate, the credits have a $25 \%$ interest from the base lending rate. The 
program is addressed to the producers from: agriculture, hunting, forestry, fishing, pisciculture and the processing industry. The Apuseni Mountains inhabitants can benefit from credits in euro with a $7.5 \%$ interest for the development of activities in agriculture. The available funds' total value for this project is 16.4 million euro.

For grants, NASMEC has identified 20 programs that the SMEs can use to access nonrefundable funds, for sectors like human resources, tourism, agriculture, IT or scientific and technological parks. After identifying the credit source, the main problem that needs solving is guarantying the loan. In order to do this, small businesses can turn to the National Credits Guarantying Fund for SMEs. After the analysis of the credit documents, in case the bank thinks the project is viable, but there aren't enough material guarantees, it will ask the Fund to participate in splitting the risk by offering a warranty. After an analysis, the Fund will decide on whether to offer or not a warranty. In case of an affirmative answer, the bank and the Fund will sign a guarantee contract, which will constitute the base for the bank to sign the contract with the solicitant of the credit. Between 2002 and 2004, the Fund approved guarantees with a total value of 724.26 billion lei.

Between 2007 and 2013, almost 350.000 SMEs will be able to access 3.6 billion euro within the framework of the EU innovation sustainment and economic growth program. The new program will support actions meant to stimulate the industry and enterprises to be innovative. The program will also promote energy efficiency and alternative energy sources, environment-friendly technologies and a better use of the information and communication technology (ICT).

The first "Competitiveness and Innovation Program" (CIP) constitutes a coherent and integrative answer to the strategic objectives of the revised Lisbon Strategy. The program will cover the 2007-2013 period and will have a 3.6 billion Euros budget, which means a $60 \%$ growth of the annual expenses for actions dedicated to competitiveness and innovation until 2013, compared to 2006.

The CIP program has the following objectives:

- the growth of the enterprises' competitiveness, especially SMEs;

- promoting all forms of innovation, including eco-innovation;

- the accelerating development of a durable, competitive, innovative and inclusive Informational Society;

- promoting energy efficiency and alternative energy sources in all sectors, including transportation.

Eco-innovation will constitute a transversal theme for the entire program.

CIP has three specific programs:

(1) starting and developing SMEs: "The Entrepreneurial and Innovation Program" with a budget of 2.17 billion Euros, including 430 million Euros for the promotion of eco-innovation, will facilitate the SMEs' access to financing, to a better integration of the present services networks for the development of businesses (Euro Info Centers and Relay Innovation Centers) and will support innovative activities (INNOVA, Pro-Inno, etc.). Over 1 billion Euros will be allocated for the promotion of the successful financial instruments managed by the European Investment Fund (EIF).

(2) Information and communication technology: "The ICT Policy Support Program", with a budget of 730 million Euros, will sustain competitiveness, economic growth and labor force employment through the stimulation of the embracement and the larger and more efficient use of the information and communication technology. The program will especially sustain pilot-actions that are based on ICT innovative and public interest services, on the development of the digital content and on the improvement of the security and trust in ICT and its applications. 
(3) A better use of the alternative energy sources and energy consumption's reduction: "Intelligent Energy-Europe Program", with 730 million Euros budget, will sustain energy efficiency, new and alternative energy sources and technological solutions for the green-house emissions' reduction in the transportations sector.

Studies show the value of the EU support regarding the credit guarantees, thus every euro from the community's budget has lead to a loan volume of 72 Euros. On average, every company sustained by a risk capital fund maintains and creates over 50 work places.

Non-profit foundations, European organisms or Romanian state institutions have created programs for training, consultancy and professional development. On the other hand, the SMEs which activate in the non-energetic extractive industry, in the processing industry or in constructions will be able to receive regional state aid for investments. There will be a co-financing of investment projects with a value between 200.000 and 1.5 million Euros, which wish to create new companies or to extend existent companies, to diversify production or to extend production capacity, to modernize companies, to introduce new technologies, to acquire patents or licenses etc. Among the necessary financing conditions are: the acquired goods must be new and the project must take place on Romanian territory. Financing will not be granted for projects that have started implementation, or when the beneficiary doesn't prove the financing necessity. In other words, it must be proved the project can't be implemented with own efforts solely, and the evaluation will take into account the level of the distributed dividends to the stock-holders in the last years, based on the account balance.

For investment projects up to 200.000 Euros the support will be offered through a minimis aid scheme, which has a maximum level of 100.000 Euros in a three years time period.

A Private Small and Medium-seized Enterprises National Council survey shows that over $52 \%$ of the 900 interviewed entrepreneurs think that bureaucratic and difficult procedures restrict the access to non-refundable financing from the European Union or from other sources.

Still, 32.7\% of the entrepreneurs accessed European or national grants. On the other hand, $62.1 \%$ of the respondents accuse that financing programs are not really addressed to SMEs, because they don't have the capacity to co-finance the projects with 50 or $60 \%$.

Entrepreneurs considered satisfactory only two of the seven performance types of entrepreneurial policies in Romania, studied by the experts from the Organization for Economic Co-operation and Development (OECD) and the European Bank for Reconstruction and Development (EBRD). The business environment still has work to do in the "Consultancy Services" and "Financial Systems" departments.

In Romania there are approximately 370.000 active SMEs, which should have had programs for almost 5.000 billion lei from the state budget, according to the SMEs law. But only 1.4000 billion lei were allocated. When the OECD-EBRD study was presented, the government promised it will try to double this figure. According to the opinion of the European Commission experts, it is necessary to have bureaucracy when accessing nonrefundable funds; because it must be proved that the money of the European tax payers is spent properly.

In conclusion, the European Union supports the development of the SMEs sector through multiple viable financial instruments, which must be seen by our country as real developing and competitiveness opportunities at national and international level.

\section{Bibliography:}

1. Dănulețiu D.C-tin, Fundamente ale economiei europene, Editura Risoprint, Cluj Napoca, 2005; 
2. Moise I. Achim, Managementul Afacerilor, Note de curs, Universitatea „1Decembrie 1918,, Alba Iulia, 2006 www.finantare.ro

www.mie.ro 